\title{
A organização do conhecimento em ambientes digitais: aplicação da teoria da classificação facetada
}

\section{Flavio Vieira Pontes}

\begin{abstract}
Doutorando pelo Programa de Pós Graduação em Ciência da Informação da Universidade Federal de Minas Gerais Professor nas áreas de Banco de Dados, Engenharia de Software e Programação Web, na Faculdade de Viçosa - FDV.
\end{abstract}

Gercina Ângela Borém de Oliveira Lima

Doutora em Ciência da Informação pela Universidade Federal de Minas Gerais (UFMG). Professora adjunta da Escola de Ciência da Informação da Universidade Federal de Minas Gerais (UFMG).Vice-presidente da ISKO-Brasil

Partindo da constatação de que os conhecimentos desenvolvidos pela Biblioteconomia e a Ciência da Informação não têm sido amplamente aplicados ou adaptados para o ambiente digital, apresenta-se uma abordagem baseada na classificação facetada para a organização de acervos digitais. Apresenta-se, inicialmente, buscando o esclarecimento conceitual, os conceitos de informação e conhecimento, bem como da organização da informação/conhecimento. Em seguida, é brevemente discutida a importância dos esquemas classificatórios na representação e organização do conhecimento, buscando facilitar a descoberta e recuperação da informação. É apresentada, em seguida, a Teoria da Classificação Faceta, além de discutida a sua aplicação, como mecanismo para organização do conhecimento em ambientes digitais. Objetiva-se a criação de mecanismos mais eficazes para a navegação e exploração destes acervos, de modo a facilitar a recuperação da informação nestes ambientes. Ao final, são apresentados os resultados iniciais da pesquisa, que busca avaliar a aplicação de uma taxonomia facetada para a organização do conhecimento, em uma biblioteca digital de teses dissertações. 
Palavras-chave: Organização do conhecimento; Teoria da classificação facetada; Bibliotecas digitais; Taxonomia facetada.

\title{
Knowledge organization in digital environments: faceted classification theory applied
}

\begin{abstract}
Starting from the perception that the knowledge developed by the Library Science and the Information Science have not been amply applied and adapted for the digital environment, we present an approach based on the faceted classification for the organization of digital collection. First, we search for the clarification of the concepts of information and knowledge as well as the organization of information-knowledge. Then we discuss briefly about the importance of the classifying schemes of representation and organization of knowledge in order to facilitate the finding and retrieval of information. Besides, we present the Theory of Faceted Classification, and discuss about its application as a mechanism for the organization of knowledge in digital environments. This aims to create more efficient mechanisms for the navigation and exploration of these collections, so as to make it easier the information retrieval in these environments. Finally, we present the first results of our research, which tries to determine the value of the application of a faceted taxonomy for the organization of the knowledge in a digital library of theses and dissertations.
\end{abstract}

Key words: Knowledge organization; Theory of faceted classification; Digital libraries; Faceted taxonomy.

Recebido em 15.09.2011 Aceito em 10.12.2012

\section{Introdução}

Diversos autores têm observado que uma série de conhecimentos acumulados sobre como organizar bibliotecas e como tratar informações não está sendo devidamente aproveitada no contexto digital. Aparentemente, as teorias e técnicas desenvolvidas pela biblioteconomia, ao longo dos anos, não vêm sendo amplamente aplicadas e ou adaptadas para o contexto das bibliotecas digitais. Isso ocorre, principalmente, no que diz respeito ao uso de estruturas de representação e organização do 
conhecimento. A abordagem de busca textual (full-text) predomina como mecanismo hegemônico para a recuperação da informação nestes ambientes. Colocando a parte o componente tecnológico, que potencializa o acesso a partir do momento que retira as barreiras de tempo e espaço, observa-se que as bibliotecas digitais não proporcionam a mesma eficácia das bibliotecas tradicionais no que se refere à recuperação da informação. Podemos dizer que bibliotecas digitais são, na maioria dos casos, meros sistemas executores de consultas, que devem ser formuladas e objetivadas por seus usuários.

Compartilhamos do entendimento de que a biblioteca digital possui os mesmos objetivos da biblioteca tradicional e que deveria se basear nos mesmos princípios, teorias e técnicas desenvolvidas pelo campo da Biblioteconomia e Ciência da Informação. O conceito de biblioteca digital constitui um subconjunto de um conceito mais extenso de biblioteca e não um substituto para ele. Todos os valores e funções da biblioteca continuam válidos, o que mudam são os objetos físicos que formam suas coleções e, naturalmente, o instrumental tecnológico para manipulá-los. De acordo com Sayão (2009), a informação digital não é antagônica à informação impressa, mas, também, não é a sua mímica. O seu surgimento muda muita coisa. A substituição de papel pelo documento digital está assentada em algumas importantes diferenças, entre elas o nível de granularidade no qual é possível tratar as informações digitais e nas suas possibilidades de recuperação e acesso. Bibliotecas digitais incluem todos os processos e serviços oferecidos pelas bibliotecas tradicionais, embora esses processos tenham que ser revisados para acomodar diferenças entre mídias digitais e impressas. Como afirma Sayão (2009, p. 16), "o digital não é o antagônico do impresso, como o rolo de papiro não é o antagônico do livro. Para cumprir o seu papel ancestral a biblioteca sempre se apropriou das mais avançadas tecnologias disponíveis e vem continuamente evoluindo no ritmo dessas tecnologias". No que se refere a nossa pesquisa, estamos interessados na organização do acervo digital, bem como no sistema de biblioteca digital e nas funcionalidades relacionadas à recuperação da informação, funcionalidades estas que se apoiam na organização do acervo.

Diante do exposto, acreditamos que as bibliotecas digitais fornecem uma condição necessária, mas não suficiente para a efetiva comunicação, disseminação e compartilhamento do conhecimento. Estas bibliotecas carecem de mecanismos mais eficazes para a exploração do acervo e recuperação da informação. Serão apresentadas as bases teóricas da classificação facetada, além de discutidas suas vantagens em relação a outras estruturas classificatórias, bem como a sua aplicação para a organização de acervos em ambientes digitais. Nossa pesquisa tem como objetivo implementar novos mecanismos para a representação e organização do acervo de uma biblioteca digital de teses e dissertações, com base em uma estrutura classificatória facetada e em taxonomias dinâmicas. Objetiva, também, avaliar o desempenho desses mecanismos na melhoria da recuperação da informação e na satisfação do usuário. 
A seguir, será realizada uma breve discussão acerca do uso dos conceitos de informação e conhecimento, bem como da organização da informação/conhecimento, buscando o esclarecimento conceitual. Em seguida, será brevemente discutida a importância dos esquemas classificatórios na representação e organização do conhecimento, buscando facilitar a descoberta e recuperação da informação. Finalmente, será apresentada a Teoria da Classificação Facetada, além de discutida a sua aplicação, como mecanismo para organização do conhecimento em ambientes digitais. Objetiva-se a criação de mecanismos mais eficazes para a navegação e exploração destes acervos, de modo a facilitar a recuperação da informação nestes ambientes. Ao final, serão apresentados os resultados iniciais de nossa pesquisa, na qual foi desenvolvido um protótipo para um sistema de biblioteca digital de teses e dissertações.

\section{Organização da informação ou do conhecimento?}

Observa-se, na literatura, certa confusão na utilização de conceitos
como informação, conhecimento e organização de informação/conhecimento. Bräscher e Café (2008) analisaram as ambiguidades no emprego das seguintes expressões, no contexto da Ciência da Informação: organização do conhecimento (OC); organização da informação (OI); representação do conhecimento (RC); e representação da informação (RI). Segundo as autoras, "no contexto da OI e da RI, temos como objeto os registros de informação. Estamos, portanto, no mundo dos objetos físicos, distinto do mundo da cognição, ou das idéias, cuja unidade elementar é o conceito" (BRÄSCHER; CAFÉ, 2008, p. 5). As autoras apresentam uma proposta de distinção entre os dois processos de organização:

[...] um que se aplica às ocorrências individuais de objetos informacionais - o processo de organização da informação - e outro que se aplica às unidades do pensamento (conceitos) o processo de organização do conhecimento. A OI compreende, também, a organização de um conjunto de objetos informacionais para arranjá-los sistematicamente em coleções, neste caso, temos a organização da informação em bibliotecas, museus, arquivos, tanto tradicionais quanto eletrônicos. A organização do conhecimento, por sua vez, visa à construção de modelos de mundo que se constituem em abstrações da realidade (BRÄSCHER; CAFÉ, 2008, p. 6).

Hodge (2000) para englobar dicionários, glossários, arquivos de autoridade, taxonomias, sistemas de classificação, cabeçalhos de assunto, tesauros, redes semânticas e ontologias. Bräscher e Café (2008) ressaltam que esses sistemas de organização de conhecimento são "o coração de toda biblioteca, museu e arquivo", uma vez que são 
"mecanismos de organização da informação" (BRÄSCHER; CAFÉ, 2008, p. $8)$.

A representação, seja ela de informação ou conhecimento, é condição necessária para a organização, na medida em que se torna mais fácil manipular as representações do que os objetos representados. A organização da informação ou conhecimento compreende um processo de representação e destina-se, prioritariamente, à recuperação eficaz por parte dos usuários. O objetivo do processo de organização da informação é possibilitar e facilitar o acesso à informação, que, por sua vez, tem a competência e a intenção de produzir conhecimento (BARRETO, 2002). No entanto, nesse processo de organização da informação, faz-se uso de mecanismos (ou sistemas) de organização do conhecimento. Como afirma Vickery (2010), organizar o conhecimento é reunir o que conhecemos em uma estrutura sistematicamente organizada. Entendemos que a organização do conhecimento é condição necessária para a organização da informação, ou mais especificamente dos recursos informacionais, sob o aspecto do conteúdo dos mesmos. A organização do conhecimento produz representações sistematizadas de conhecimento, que podem ser utilizadas na organização da informação, para padronizar as representações dos conteúdos dos recursos informacionais, visando facilitar a recuperação e o uso dos mesmos.

Neste texto, estamos interessados em ambos os processos, organização do conhecimento e da informação. Estamos interessados na adoção de um sistema de organização do conhecimento, estruturado na forma de uma classificação facetada, para a organização da informação em ambientes digitais.

\section{As classificações e a representação do conhecimento}

Bibliotecas digitais, assim como as convencionais, fazem uso de diversos mecanismos e estruturas, a fim de imprimir certo grau de organização em seu acervo, visando facilitar a descoberta e recuperação da informação. A organização do conhecimento pressupõe alguma forma de representação. Esquemas de classificação possuem características que possibilitam a representação de entidades e relacionamentos em estruturas que refletem o conhecimento do domínio sendo classificado. Kwasnik (1999), ao analisar a relação entre as classificações e a representação do conhecimento, afirma que, na medida em que os conceitos se aglutinam e os relacionamentos entre os mesmos são entendidos, um esquema de classificação pode ser usado como uma rica representação do que é conhecido e, desta forma, ser útil na comunicação e na geração de ciclos sucessivos de exploração, comparação e teorização. A autora conclui que um bom esquema de classificação funciona da mesma forma que uma teoria, conectando conceitos dentro de uma estrutura útil. Uma classificação bibliográfica é um sistema de codificação e organização de materiais bibliográficos de acordo com seus assuntos. Em uma biblioteca convencional, uma classificação consiste geralmente de 
tabelas de assuntos ou estruturas classificatórias utilizadas na atribuição de um número de classe (notação) a cada item do acervo, com base no seu assunto. Existem diversos tipos de estruturas classificatórias. Kwasnick (1999) identifica quatro tipos básicos de estruturas classificatórias: hierarquias, árvores, paradigmas e facetas. Cada tipo de estrutura se baseia em uma determinada abordagem estrutural e em pressupostos filosóficos, visando determinar o conjunto dos conceitos tratados pelos documentos de uma coleção. Sob o ponto de vista estrutural, nos esquemas de classificação enumerativos, cada assunto é subdividido até que todas as possibilidades (conhecidas) sejam previstas. A cada subdivisão ou classe, é associado um número identificador (notação). Em uma classificação hierárquica, cada classe é subdividida e as classes resultantes são ordenadas a partir do geral para o específico. Já uma classificação facetada, apresenta uma abordagem alternativa, na medida em que divide os assuntos em categorias ortogonais e mutuamente exclusivas, a partir do uso da técnica da análise facetada. Segundo Vickery (1960), independente do tipo de estrutura, todas as classificações possuem os mesmos propósitos: (1) normalizar a linguagem dos documentos, por um lado, e a linguagem das consultas por outro (no contexto de um sistema de recuperação da informação); (2) servir como um mecanismo útil ao indexador na tarefa intelectual de caracterizar o conteúdo temático ou assunto de um documento; e (3) atuar como uma ferramenta do usuário na tarefa de analisar e definir suas estratégias de busca ao acervo.

Nas próximas seções, será apresentada a Teoria da Classificação Facetada e discutida a sua aplicação como mecanismo para organização do conhecimento em ambientes digitais.

\section{A Teoria da Classificação Facetada}

As classificações facetadas representam uma abordagem alternativa para o processo classificatório, através da análise facetada. O processo utilizado na análise facetada tem suas origens em Shiyali Ramamrita Ranganathan (GARFIELD, 1984), um pesquisador indiano que propunha que qualquer entidade complexa poderia ser representada a partir de certo número de perspectivas ou facetas. Para Ranganathan, o problema dos sistemas de classificação tradicionais, como a Classificação Decimal de Dewey e os Cabeçalhos de Assunto, é que as classes ou os termos usados precisam ser elaborados antes dos objetos serem classificados. Além disso, estes sistemas não se mostravam adequados para a representação de assuntos compostos. Com o grande desenvolvimento científico e proliferação da informação observada no século $X X$, estes sistemas enumerativos ou pré-coordenados não eram adequados. Ao invés de criar compartimentos para depois colocar os objetos dentro dos mesmos, Ranganathan buscava uma forma de partir do objeto e, então, coletar e arranjar aspectos (ou facetas) que pudessem descrever aquele objeto. Essa abordagem possibilita maior flexibilidade e um alto grau de especificidade no sistema de classificação. Ao longo dos anos, as ideias de 
Ranganathan foram reinterpretadas, desenvolvidas e utilizadas em diversos contextos, envolvendo representação, organização e recuperação da informação.

Desde os primórdios da classificação e indexação, como aponta Broughton (2006), pode-se observar a recorrência regular de atributos comuns, como lugar, tempo e forma. Uma das principais contribuições de Ranganathan foi constatar que não só existiam conceitos recorrentes em praticamente todas as áreas, como, também, existiam tipos recorrentes de conceitos dentro destas áreas (BROUGTON, 2006). Alguns representavam atividades ou ações, que Ranganathan chamou de Energia; outros conceitos eram relativos a substâncias, ou seja, Matéria; os conceitos nucleares, que representam os principais objetos de estudo de uma disciplina, representando a sua essência, foram agrupados na categoria Personalidade por Ranganathan. Os membros dessa categoria são, na maioria das vezes, entidades, como plantas, animais, componentes químicos, corpos celestes, formações geográficas, religiões, objetos manufaturados, etc. Adicionando as categorias comuns Espaço e Tempo, chegamos às cinco categorias fundamentais propostas por Ranganathan e conhecidas pela sigla PMEST (Personality, Matter, Energy, Space e Time). Dentro de uma disciplina ou campo de estudo, todos os conceitos ou termos poderiam ser organizados nessas cinco categorias. Ranganathan argumentava que qualquer objeto (ou qualquer conceito ou assunto de um objeto de informação) poderia ser representado através da seleção de elementos dessas cinco categorias. Por exemplo, se considerarmos um livro sobre "o projeto de casas de madeira no sul do Brasil no início do século XX", teríamos as seguintes facetas:
a)personalidade (Personality) - casas;
b)matéria (Matter) - madeira;
c)energia (Energy) - projeto;
d)espaço (Space) - sul do Brasil; e
e)tempo (Time) - início do século XX.

O exemplo, acima, é intencionalmente simples. Todas as cinco categorias foram utilizadas, sendo que cada uma foi utilizada uma única vez. Nem todas as categorias precisam ser necessariamente utilizadas e uma mesma categoria pode ser utilizada mais de uma vez para descrever adequadamente um objeto.

O Classification Reseach Group (CRG), grupo de pesquisadores que se estabeleceu na Inglaterra, a partir de 1952, com o objetivo de realizar estudos sobre a natureza do processo classificatório e das classificações existentes (SPITERI, 1998), considerou essas categorias limitadas para representar algumas disciplinas e expandiu as categorias fundamentais em 13: thing, kind, part, property, material, process, operation, agent, patient, product, by-product, space, e time. Essas categorias poderiam acomodar os conceitos da maioria das disciplinas, apesar de que disciplinas, como arte e humanidades, requerem categorias adicionais 
(como forma, estilo, gênero) e não há nada que impeça que novas categorias fundamentais possam ser definidas ou inventadas (BROUGTON, 2006). Um esquema de classificação facetado é um conjunto mutuamente exclusivo e exaustivo de categorias combináveis, no qual cada categoria é obtida a partir do isolamento de uma perspectiva (ou faceta) dos itens a serem classificados, que, combinadas, descrevem todos os itens em questão; e que os usuários podem utilizar, no processo de busca e navegação, de modo a encontrar aquilo que procuram.

Uma característica pouco explorada nos esquemas de classificação facetados são os relacionamentos entre conceitos. Um esquema facetado tem a capacidade de expressar tais relacionamentos, sejam os relacionamentos entre conceitos dentro de uma mesma faceta (relacionamentos semânticos), bem como os relacionamentos entre conceitos de diferentes facetas (relacionamentos sintáticos). Quando se considera os relacionamentos dentro de uma mesma faceta, todos os conceitos estão em uma mesma categoria (são todos ou entidades ou processos ou lugares, etc.). Os relacionamentos entre esses conceitos são basicamente hierárquicos, incluindo conceitos genéricos, específicos e coordenados. Os esquemas facetados se diferenciam quando se considera seu potencial de combinar conceitos de diferentes facetas. E é neste ponto, que uma das principais características desses esquemas aparece: os relacionamentos entre facetas e entre conceitos de diferentes facetas os relacionamentos interfacetas (BROUGTON, 2006). O número e a variedade destes relacionamentos são exclusividade dos esquemas facetados e, como aponta Broughton (2006), apesar dos relacionamentos serem raramente objeto de discussão, eles representam um alto grau de sofisticação. Considerando-se uma estrutura facetada que utilize 8 categorias ou facetas principais, teremos um número total de 56 relacionamentos interfacetas em potencial, do tipo "agente-operação", "processo-produto", etc. O Quadro 1, abaixo, ilustra os dois tipos de relacionamentos presentes em um esquema facetado.

QUADRO 1 - Relacionamentos presentes em um esquema facetado

executam

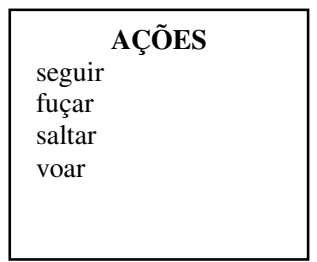

são controlados com

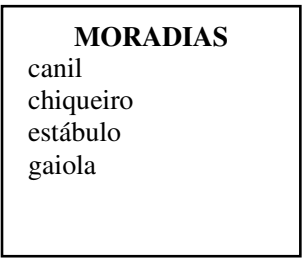

Fonte: Adaptado de BROUGHTON (2006).

A identificação de relacionamentos intra e interfacetas, apresentados por Broughton (2006), se alinha com a distinção entre relacionamentos "paradigmáticos", que são inerentes à natureza dos conceitos e são válidos em qualquer situação; relacionamentos "sintáticos" ou 
"sintagmáticos", que são aqueles que ocorrem quando vários conceitos são reunidos no contexto de um dado documento para a descrição de seu assunto. Desta forma, os relacionamentos entre conceitos, dentro de uma mesma faceta, são, em geral, relacionamentos paradigmáticos, enquanto os relacionamentos entre conceitos de diferentes facetas são normalmente sintagmáticos (BROUGHTON, 2008).

QUADRO 2 - Relacionamentos paradigmáticos e sintagmáticos

\begin{tabular}{|l|c|c|c|}
\hline Faceta & Entidades & Operações & Agentes \\
\hline $\begin{array}{l}\text { Relacionamentos } \\
\text { paradigmáticos entre } \\
\text { termos do vocabulário }\end{array}$ & Cereais & Cultivo & Máquinas agrícolas \\
\cline { 2 - 4 } & Trigo & Colheita & Colheitadeira \\
\cline { 2 - 4 } & \multicolumn{2}{|c|}{} \\
\cline { 2 - 4 }
\end{tabular}

Fonte: Adaptado a partir de BROUGTON (2008).

A Teoria da Classificação Facetada é importante por fornecer uma metodologia racional para a construção de esquemas de classificação, em contraste com o agrupamento pragmático de classes, que caracteriza as classificações desenvolvidas no passado (HJORLAND, 2002). Segundo Hjorland (2007), a classificação facetada é a única forma de organizar os conceitos de um domínio que possui uma base racional e lógica. Neste sentido, a classificação facetada teve sua influência sentida nos principais instrumentos convencionais da classificação bibliográfica, como analisado por Broughton (2006), nas políticas e diretrizes para as versões mais recentes da Classificação Decimal de Dewey, da Classificação Decimal Universal e dos Cabeçalhos de Assunto da Biblioteca do Congresso Americano.

\section{Considerações sobre diferentes visões e uso da classificação facetada}

Observa-se, na literatura recente, uma visão diferenciada sobre o conceito de facetas. Tal visão estende o entendimento do que vem a ser uma faceta, de modo a incorporar vários aspectos não semânticos de um documento. A norma NISO afirma que "a análise facetada é, às vezes, usada para indicar atributos de objetos de informação" (NATIONAL INFORMATION STANDARDS ORGANIZATION, 2005, f. 14) e lista, em seguida, as seguintes facetas potenciais: tópico, autor, localização, formato, idioma e local de publicação. Essa lista apresenta muitos aspectos em comum com o projeto Faceted Application of Subject Terminology (FAST) (CHAN et al., 2001), na medida em que "tópico" (ou assunto) é visto como uma faceta entre várias outras que representam elementos da descrição bibliográfica não relacionados ao assunto. Essa visão de faceta parece ser equivalente ao conceito de atributo de uma entidade (documento), no modelo Entidade-Relacionamento (NAVATHE; 
ELMASRI, 2003) ou no FRBR (IFLA STUDY GROUP ON THE FUNCTIONAL REQUIREMENTS FOR BIBLIOGRAPHIC RECORDS, 1998). Nesse sentido, essas "facetas" podem ser facilmente mapeadas nos campos do MARC ou nos elementos do padrão de metadados Dublin Core. Broughton (2006) assinala que esse tipo de aplicação da classificação facetada parece ser exclusivo dos pesquisadores americanos. Dessa forma, parece haver duas visões distintas da classificação facetada: (A) Um conjunto de "entidades" é classificado de acordo com suas propriedades. Por exemplo, um conjunto de vinhos é classificado por "cor", "origem", "variedade de uva", "ano de produção", "preço" e "qualidade". Nesse caso, cada uma dessas propriedades representa uma "faceta", através da qual um conjunto de instâncias (vinhos) pode ser visualizado. (B) Um conjunto de "conceitos" é agrupado de acordo com o seu tipo mais primitivo. Por exemplo, o conceito "madeira" é colocado na faceta "materiais". O conceito "inseto", por sua vez, é colocado na faceta "organismos". Nesse caso, uma faceta é essencialmente uma classe primitiva e cada membro do agrupamento representado pela faceta é uma instância ou subclasse dessa classe primitiva.

As duas visões parecem ser consequência da diferença entre "classificar entidades" e "classificar conhecimento". Quando se considera a classificação de documentos, as duas visões ficam ainda mais evidentes, visto que um documento tanto pode ser visto como uma entidade, possuindo propriedades (ou atributos), tais como forma, idioma, data de publicação, bem como pode ser visto como uma forma de representação de informação e conhecimento a serem compartilhados. Nesse último caso, o conhecimento pode ser classificado de modo a facilitar o acesso ao documento e seu conteúdo. Em suma, se o intuito é a classificação de objetos/entidades (vinhos, câmeras fotográficas, carros, softwares), então, a estrutura classificatória resultante será baseada na visão A. Por outro lado, se a intenção é classificar o conhecimento, então existirão facetas fundamentais em um nível mais alto de abstração, de modo a permitir a organização dos conceitos de acordo com a visão B.

Uma vantagem de uma visão ampliada da classificação facetada (visão $A+B$ ) pode estar na possibilidade de desenvolvimento de um modelo único de busca e navegação, baseado na Teoria da Classificação Facetada, que incorpore tantos os aspectos semânticos (temáticos) como os aspectos descritivos dos documentos. Nesse sentido, a Teoria da Classificação Facetada atuaria como alicerce comum, na medida em que serviria tanto à representação temática dos documentos, em um determinado campo de estudo, como, também, poderia incorporar os elementos da representação descritiva, usualmente representados por meio de padrões de metadados. Essa possibilidade foi explorada em nossa pesquisa. 


\section{As classificações facetadas e sua aplicação em ambientes digitais}

Os esquemas de classificação são, muitas vezes, considerados pouco efetivos e inadequados para a organização de recursos digitais $(\mathrm{KOCH}$, 1998). As razões para isso estão na falta de estrutura lógica observada nos esquemas de classificação oriundos da tradição biblioteconômica. Esses esquemas são construídos, na maioria das vezes, em uma estrutura hierárquica, com ênfase na sucessiva divisão em classes mais específicas. Nesse tipo de estrutura, os únicos relacionamentos identificados são os hierárquicos, sendo que não existe suporte para relacionamentos sintáticos BROUGHTON (2002). Como consequência, o esquema de classificação é geralmente extenso, não havendo mecanismos para a combinação de classes ou para a representação de assuntos compostos e complexos. Esses problemas se acentuam quando se considera domínios interdisciplinares ou conteúdos complexos, como é o caso da área científica.

As classificações construídas de acordo com o modelo analítico facetado representam uma alternativa, na medida em que operam sob princípios distintos, partindo dos conceitos constituintes de um assunto, em contrapartida a uma visão totalizada e rígida do conhecimento. Essas classificações podem ser usadas em ferramentas para controle de vocabulário, descrição temática de documentos e na recuperação. Uma classificação facetada traz diversas vantagens quando aplicada na forma de um mecanismo de organização para o acesso a recursos digitais. 0 formato lógico e previsível da classificação facetada se torna bastante intuitivo e útil ao usuário, podendo ser usada na construção da interface de navegação e exploração do acervo, como alternativa à estrutura hierárquica de diretórios típica das classificações tradicionais. As classificações facetadas podem fornecer pontos de acesso multidimensionais flexíveis e altamente estruturados aos documentos.

Quando se considera a aplicação de esquemas facetados em ambientes digitais, a ordem de citação adquire menor importância, dada a flexibilidade e facilidade com que o usuário pode fazer uso da interface do sistema, a fim de estabelecer as categorias a serem utilizadas na busca ou navegação. Diversos autores (GODERT, 1991; INGWERSEN; WORMELL, 1992; ELLIS; VASCONCELOS, 2000) reconhecem que os esquemas facetados são adequados para o uso em ambientes digitais, especialmente na $W e b$, onde todo o seu potencial pode ser explorado. Ingwersen e Wormell (1992), ao analisar o uso de estruturas facetadas para recuperação da informação em bancos de dados, afirmaram que:

[...] a discussão demonstra a utilidade da categorização facetada, não apenas para documentos textuais, mas também para outras formas de conteúdos. A categorização facetada pode fornecer pontos de acesso multidimensionais e estruturados para o conteúdo dos documentos, e desta forma possibilitar o acesso intelectual ao conhecimento gerado e 
armazenado (INGWERSEN; WORMELL, 1992, p. 199, tradução nossa).

Segundo Kwasnick (1999, p. 39), "A noção de facetas se assenta na crença de que existe mais de uma maneira de ver o mundo, e que mesmo as classificações que são tidas como estáveis, são de fato provisórias e dinâmicas. O desafio é construir classificações que sejam flexíveis e que possam acomodar novos fenômenos". Denton (2003) acrescenta que, depois que o esquema de classificação é construído, o desafio é tornar seu uso fácil e intuitivo. Com o hipertexto e a $W e b$, variadas visões podem ser dinamicamente construídas. As facetas possibilitam um esquema organizacional multidimensional que, com 0 uso de ferramentas disponíveis em ambiente digital e na $W e b$, pode ser facilmente consultado e navegado em suas diversas dimensões, de modo que todos os benefícios das classificações facetadas podem ser aproveitados nestes ambientes.

Broughton (2006) nos lembra que, no ambiente digital, o arranjo linear dos materiais ou de suas representações não é tão importante. Apesar da ordem de apresentação na tela ser importante, a ordem física dos itens no repositório não é importante. No ambiente digital, o objetivo da organização da informação não é o arranjo físico dos materiais, mas sim a adequada descrição dos mesmos, rotulagem com vistas à recuperação, fornecimento de ferramentas de busca, navegação e recuperação e, finalmente, a apresentação dos resultados.

La Barre (2006) observou o crescente interesse pela análise e classificação facetada entre profissionais, como arquitetos da informação atuando no projeto de sites web e especialistas em gestão do conhecimento, atuando na construção de mecanismos para facilitar a gestão e o acesso ao conhecimento organizacional. Parte destes profissionais utiliza explicitamente a terminologia, sugerindo 0 embasamento nos princípios inicialmente propostos e desenvolvidos por Ranganathan, outros, nem tanto. Apesar do uso da terminologia não significar necessariamente evidência de que as estruturas organizacionais desenvolvidas por estes profissionais estejam alinhadas com os princípios teóricos da classificação facetada, seu uso é indicativo da adoção destes princípios e pode indicar áreas nas quais as estruturas de organização e acesso podem ser aperfeiçoadas pela aplicação consistente da teoria. Esta situação, também, pode revelar novas áreas da prática profissional que podem servir para aperfeiçoar a teoria, em uma abordagem simbiótica entre a teoria e a prática (LA BARRE, 2006). A pesquisa da autora buscou fazer uso da Teoria da Classificação Facetada, como ferramenta para analisar as estruturas classificatórias utilizadas em aplicações e sites na Internet, bem como avaliar até que ponto estas aplicações estão alinhadas aos princípios da classificação facetada. La Barre (2006) concluiu que a Teoria da Classificação Facetada vem sendo amplamente aplicada na arquitetura da informação de grande parte dos sites. Mais especificamente, ela vem sendo usada como mecanismo de organização 
do conteúdo e navegação. A autora aponta para a necessidade de estudos de usabilidade que possam avaliar a performance destas interfaces, bem como apontar soluções que venham a reduzir a sua complexidade. Outro ponto destacado pela autora e de interesse desta pesquisa, diz respeito a possibilidade de exploração, sistematização e formalização dos relacionamentos entre facetas.

As classificações facetadas estão se tornando cada vez mais presentes na $W e b$, principalmente em sites comerciais (ADKISSON, 2005; LA BARRE, 2006). As facetas e os esquemas que nelas se baseiam representam uma maneira natural, intuitiva e flexível de organizar coisas. Desta forma, os projetistas de sites as utilizam, na medida em que analisam as diversas formas alternativas nas quais os usuários gostariam de visualizar as informações contidas nos sites. Isto sem nada saber sobre Ranganathan, o Classification Research Group (CRC), nem sobre as décadas de estudos por traz da Teoria da Classificação Facetada. Por outro lado, os profissionais da informação conhecem a teoria, reconhecem o seu potencial de aplicação, mas não possuem os conhecimentos técnicos necessários para implementar estes sistemas no ambiente digital. Denton (2003) aponta para a necessidade de aproximar essas duas áreas de estudo e, neste sentido, sugere um processo simplificado para a criação de classificações facetadas e sua implementação na forma de sistemas na Web.

\section{Taxonomias, taxonomias facetadas e taxonomias dinâmicas}

Taxonomias são estruturas hierárquicas de categorias, desenvolvidas de forma sistemática, utilizadas como ferramenta de organização intelectual. São geralmente empregadas em portais institucionais e bibliotecas digitais como um mecanismo de consulta, ao lado de ferramentas de busca. Além dessas aplicações, a taxonomia é um dos componentes em Ontologias (CAMPOS; GOMES, 2007). A organização das informações, através de uma taxonomia, permite alocar, recuperar e comunicar informações dentro de um sistema de maneira lógica, pela navegação.

As taxonomias são geralmente desenvolvidas utilizando a abordagem enumerativa, através da segmentação do universo, na qual as categorias são dispostas em uma estrutura hierárquica e os níveis das subcategorias são definidos. A estrutura hierárquica é fácil de se compreender e usar, porém não é flexível, na medida em que cada objeto deve ser situado em uma única categoria específica na hierarquia.

Já as taxonomias facetadas, são projetadas de acordo com o modelo analítico-sintético descrito anteriormente. Tzitzikas e outros (2002) definem formalmente uma taxonomia facetada como um conjunto finito de facetas. Cada faceta consiste de uma terminologia, ou seja, um conjunto finito de termos estruturados por relação de subsunção (hierárquica). Cada faceta é projetada separadamente e modela um aspecto distinto do domínio. Com o uso de uma taxonomia facetada, cada 
objeto pode ser classificado a partir da seleção de um ou mais termos a partir de deferentes facetas.

Taxonomias dinâmicas (SACCO; TZITZICAS, 2009), também chamadas atualmente de sistemas de busca facetada, representam um modelo genérico de conhecimento, baseado em uma classificação multidimensional de objetos, que pode ser usado para compor mecanismos de busca e navegação. O modelo para taxonomias dinâmicas somente requer uma taxonomia multidimensional (que permita a classificação de um objeto por mais de um conceito), que não precisa ser necessariamente facetada. O projeto baseado na classificação facetada contribui para a construção de taxonomias dinâmicas compactas e de fácil entendimento e uso pelos usuários. Outra vantagem observada diz respeito à estabilidade e, como consequência, a pouca necessidade de manutenção da taxonomia, além de proporcionar uma estrutura mais enxuta, intuitiva e com melhor capacidade de convergência. Conclui-se, desta forma, que o projeto da taxonomia dinâmica, baseado nos princípios da classificação facetada, é desejável, mas não obrigatório.

Em nossa pesquisa, adotamos o modelo para taxonomias dinâmicas, proposto por Sacco e Tzitzicas (2009), no contexto do desenvolvimento de um protótipo para um sistema de biblioteca digital. Além disso, a taxonomia utilizada foi desenvolvida com base nos princípios da teoria da classificação facetada, no contexto do trabalho de Maculan (2011).

\section{Aplicação de uma taxonomia facetada para organização do conhecimento em uma biblioteca digital de teses e dissertações}

No caso de um sistema de biblioteca digital de teses e dissertações, ou seja, um sistema que gerencia um repositório de teses e dissertações, a representação dos assuntos dos documentos, assim como a organização do acervo visando à navegação e exibição, não pode ser satisfatoriamente conseguida com os esquemas classificatórios tradicionais. Nessas bibliotecas, o conteúdo intelectual dos documentos é bastante complexo e é necessário um nível mais profundo de indexação, tanto em termos de especificidade como de exaustividade. Uma classificação facetada fornece uma estrutura mais rigorosa para a organização dos documentos, que pode ser utilizada pelo usuário nos processos de navegação e exploração do acervo. Além disso, uma classificação facetada pode ser usada como base para construção de mecanismos que possibilitam buscas estruturadas ao acervo. Desta forma, uma classificação facetada pode representar uma alternativa tanto para a representação de assuntos, como para a organização do acervo, na medida em que possa permitir a exploração pelo usuário através da combinação de perspectivas multidimensionais, que podem, ainda, envolver uma combinação de aspectos semânticos e descritivos dos documentos.

Compartilhamos do entendimento de Lancaster (2004), de que a indexação é uma forma de classificação. Na medida em que se atribui um 
termo, que representa um conceito específico, a um documento, estamos colocando esse documento na classe representada pelo conceito. No entanto, a simples atribuição de termos de um vocabulário controlado não oferece uma estrutura adequada para organização do acervo, que possa ser utilizada na navegação e em buscas estruturadas. A solução proposta consiste do uso de uma estrutura facetada (taxonomia facetada), além de regras para a atribuição de termos que representem conceitos representativos dos variados aspectos temáticos do documento (facetas), assim como para a combinação de conceitos na representação de assuntos compostos. Desta forma, estamos elevando a indexação a um novo patamar, na medida em que a estrutura resultante pode ser utilizada na navegação e formulação de buscas estruturadas através da seleção e combinação de conceitos pelos usuários.

Conforme mencionado anteriormente, nossa pesquisa pretende determinar a influência ou impacto da organização do acervo que utiliza uma estrutura classificatória facetada, assim como da implementação de mecanismos de recuperação da informação baseado nessa estrutura, na eficácia da recuperação da informação e na satisfação do usuário da biblioteca digital. Para tanto, foi desenvolvido um protótipo para um sistema de biblioteca digital e, posteriormente, pretende-se realizar um experimento, objetivando avaliar comparativamente o protótipo construído.

Todas as etapas da pesquisa foram desenvolvidas no contexto da Biblioteca Digital de Teses e Dissertações da Escola de Ciência da Informação da UFMG (BDTD/ECI/UFMG). A Figura 1, a seguir, ilustra as principais etapas metodológicas.

Figura 1 - Etapas metodológicas

ETAPA 1 - Estudo Exploratório
Análise de ferramentas de software e esquemas de metadados.
ETAPA 2 - Desenvolvimento do protótipo computacional
2.1. Formalização matemática e implementação computacional do esquema classificatório.
2.2. Desenvolvimento dos componentes para classificação do acervo da BDTD utilizado a estrutura classificatória facetada.
ETAPA 3 - Experimento
Avaliação comparativa.

Fonte: Dados da pesquisa.

Para o desenvolvimento do protótipo computacional (Etapa 2), optamos pela utilização da plataforma DSpace ${ }^{1}$. O DSpace é um sistema gerenciador de bibliotecas digitais desenvolvido pelo grupo de bibliotecas do MIT $^{2}$ (Massachusetts Institute of Technology) em parceria com a empresa Hewlett Packard (HP). Dessa forma, o protótipo foi desenvolvido de forma acoplada ao DSpace, de modo a poder utilizar e tirar proveito das funcionalidades já disponíveis nessa plataforma. Para o

${ }^{1}$ Disponível em: <http://www.dspace.org>. Acesso em: 8 nov. 2012.

${ }^{2}$ Disponível em: <http://libraries.mit.edu>. Acesso em: 8 nov. 2012. 
desenvolvimento do protótipo, foi utilizada a linguagem de programação Java e o sistema gerenciador de banco de dados Postgres. A implementação do protótipo foi baseada no modelo genérico para taxonomias dinâmicas, conforme proposto por Sacco e Tzitzicas (2009).

O acervo, utilizado no contexto do protótipo desenvolvido, consiste das teses e dissertações que foram importadas da Biblioteca Digital de Teses e Dissertações da Escola de Ciência da Informação da UFMG. Foram importados cerca de 200 documentos, entre teses e dissertações. A taxonomia facetada foi desenvolvida no contexto da pesquisa de Maculan (2011), que investigou o uso dessa ferramenta na organização da informação, priorizando o acesso ao conteúdo detalhado dos resultados de pesquisas stricto sensu. A autora também realizou a classificação dos documentos do acervo, utilizando a taxonomia desenvolvida. Em nossa pesquisa, a taxonomia facetada serviu como instrumento de organização do conhecimento, sendo utilizada pelos componentes de busca e acesso do protótipo computacional desenvolvido. O protótipo computacional, que foi chamado TDF-Biblio ${ }^{3}$, foi desenvolvido no formato de um sistema de biblioteca digital de teses e dissertações. O mecanismo de recuperação da informação implementado foi chamado de Busca Dinâmica-Facetada. O mecanismo utiliza um modelo baseado na classificação multidimensional (facetada) dos documentos do acervo e permite a exploração e a navegação no acervo de uma forma guiada, porém não restritiva, por meio de uma interface visual fácil e intuitiva. O mecanismo de busca implementado se apresenta em duas modalidades: "Pelos Metadados" e "Pela Taxonomia Facetada".

A modalidade "Pelos Metadados" utiliza atributos descritivos, representados nos elementos de metadados Dublin Core: Orientador (advisor), Tipo do Documento (type) e Ano de Publicação (date.issued). Além desses atributos descritivos, são também utilizados aspectos temáticos dos documentos, modelados pela taxonomia facetada e representados através de novos elementos de metadados que foram criados através da qualificação do elemento "subject", quais sejam: Tema, Objeto de Pesquisa, Escopo, Ambientação, Tipo de Pesquisa, Coleta de Dados, Métodos, Fundamento Teórico, Fundamento Histórico-Conceitual e Resultados. Já na modalidade de busca "Pela Taxonomia Facetada", são utilizados apenas os aspectos temáticos das teses e dissertações que compõem o acervo. Nessa modalidade, a Taxonomia Facetada é exibida para o usuário, permitindo que ele possa navegar pela sua estrutura, selecionando os conceitos a serem utilizados na busca.

Em ambas as modalidades, as categorias são apresentadas ao usuário seguidas de um número, que aparece entre parênteses, representando 0 total de documentos classificados na respectiva categoria. O usuário pode elaborar a sua busca progressivamente, ao mesmo tempo em que pode observar o efeito que sua escolha por uma categoria determina quais outras categorias estarão disponíveis na sequência. $O$ processo de recuperação da informação pode ser visto como

\footnotetext{
${ }^{3}$ Disponível em: <http://www.tdf-biblio.ufv.br>. Acesso em: 8 nov. 2012.
} 
um processo interativo de redução ou filtragem do acervo: o usuário seleciona um foco de interesse, que restringe o acervo a partir do descarte de todos os documentos que não pertencem ao foco em questão. Apenas as categorias usadas para classificar os documentos presentes no foco de interesse, além de seus antecessores na hierarquia, são mantidas na taxonomia reduzida. Essas categorias, que sumarizam o foco de interesse atual, são somente aquelas que podem ser utilizadas para refinamentos posteriores. A partir da perspectiva de interação homemmáquina, o usuário é efetivamente guiado para atingir seu objetivo, através de uma lista clara e consistente de alternativas possíveis.

$\mathrm{Na}$ modalidade de "Busca Dinâmica-Facetada pelos Metadados", à medida que o usuário seleciona o valor em uma dada categoria (um Orientador, por exemplo), os resultados são prontamente exibidos e a estrutura é dinamicamente reconstruída para representar somente os documentos que tiveram a participação do respectivo orientador. Dessa forma, o usuário pode dar sequência em sua busca, através da seleção de valores em outras categorias (Tipo de Documento, Ano de Publicação, Tema, etc.).

Tomando como exemplo a Figura 2, a seleção da professora "Lídia Alvarenga" produzirá como resultado 14 documentos, nos quais o nome da professora aparece na qualidade de orientadora. Nesse momento, a estrutura será reconstruída para representar o resultado parcial, permitindo ao usuário visualizar a distribuição desses documentos nas demais categorias. Esse resultado pode ainda ser filtrado na sequência, através das categorias Tipo do Documento (tese ou dissertação), Data de Publicação ou, ainda, algum aspecto referente ao conteúdo do documento, como Tema, Objeto de Pesquisa, Fundamento Teórico, Metodologia, entre outros.

Figura 2 - Exemplo da Busca Dinâmica-Facetada pelos Metadados

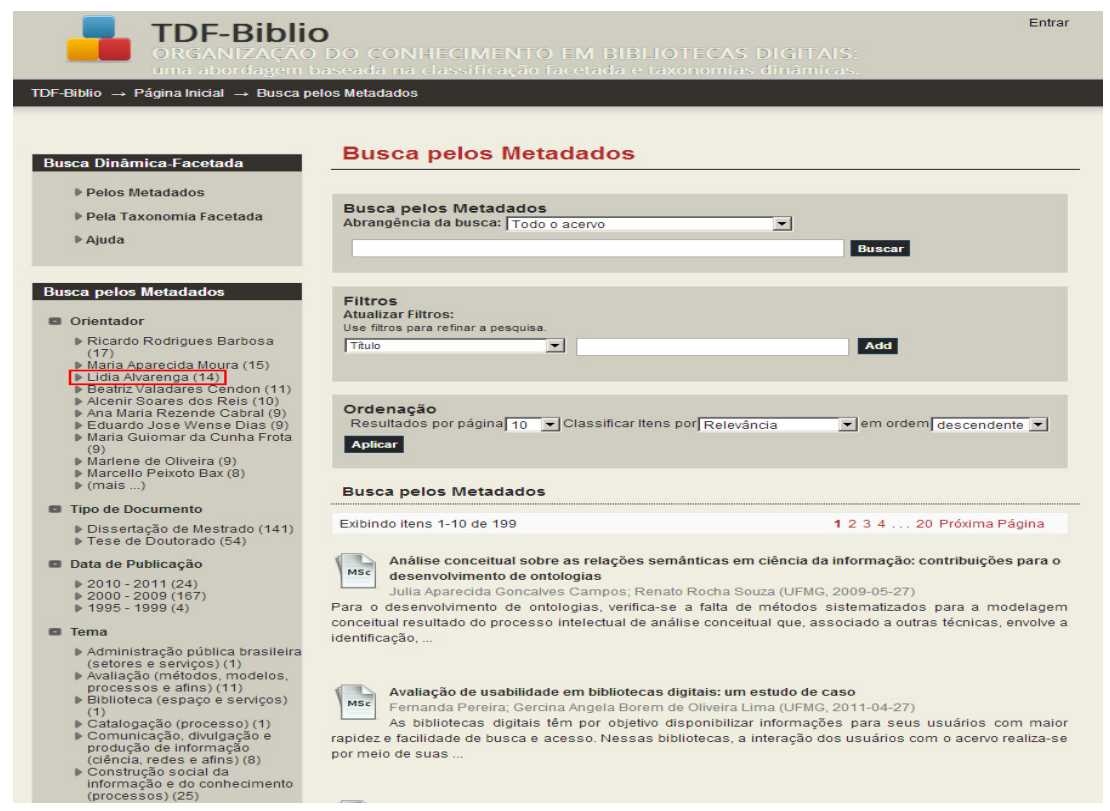

Fonte: Dados da pesquisa. 
$\mathrm{Na}$ modalidade "Busca Dinâmica-Facetada pela Taxonomia Facetada", o usuário pode navegar na estrutura hierárquica da taxonomia, selecionando opções em diferentes categorias, de modo a compor a sua busca. O resultado da busca será composto pelos documentos classificados em qualquer uma das categorias selecionadas, quando utilizado o operador OR. No caso do operador AND, o resultado será composto dos documentos classificados simultaneamente em todas as categorias selecionadas. Os resultados são exibidos e a estrutura taxonômica é dinamicamente reconstruída de modo a representar os resultados parciais exibidos. Dessa forma, o usuário pode dar sequência a sua pesquisa, fazendo o refinamento a partir da seleção de outras categorias.

Tomando como exemplo a Figura 3, a seleção de uma opção na categoria "OBJETO EMPÍRICO", fará com que sejam exibidos todos os documentos que tiveram como objeto de pesquisa a opção selecionada. $\mathrm{Na}$ sequência, a taxonomia será dinamicamente reconstruída para descrever o conjunto de resultados parciais exibidos. Assim, o usuário pode dar sequência em sua busca, selecionando, por exemplo, uma opção dentro da categoria "FUNDAMENTO TEÓRICO". Em seguida, serão exibidos como resultado, dentre os documentos que compunham o resultado parcial inicial, somente aqueles que tiveram como fundamento teórico a opção selecionada.

Figura 3 - Exemplo da Busca pela Taxonomia Facetada

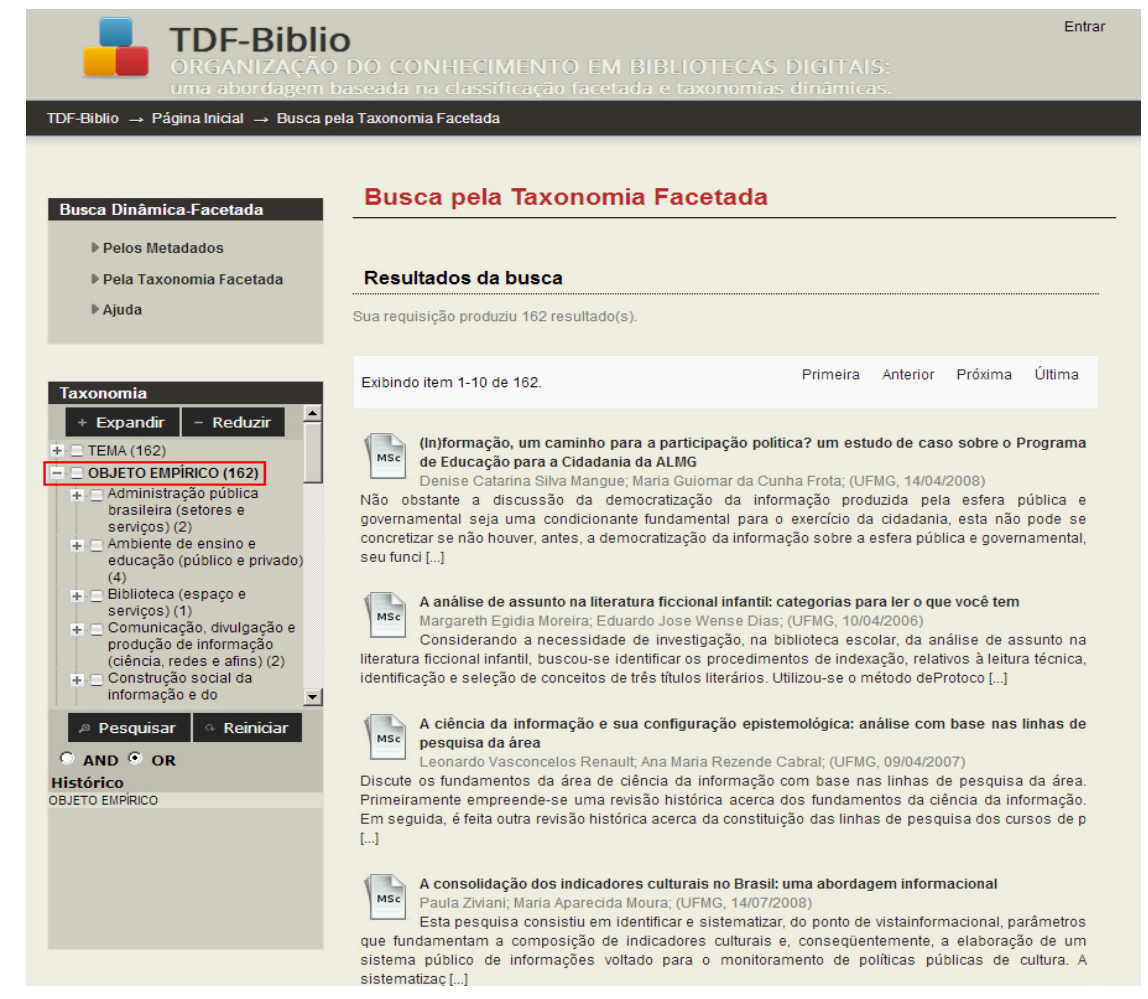

Fonte: Dados da pesquisa.

Outra funcionalidade que também foi implementada no protótipo, diz respeito à possibilidade de integração da busca dinâmica-facetada com 
a busca textual. Essa integração acontece de duas formas. No primeiro caso, o usuário pode iniciar fornecendo uma expressão para o mecanismo de busca textual, sendo que os resultados retornados pela busca textual serão dinamicamente descritos pela taxonomia. Dessa maneira, o usuário poderá dar sequência a sua busca, utilizando o mecanismo de busca dinâmica-facetada, partindo dos resultados parciais fornecidos pela busca textual. No segundo caso, o usuário pode iniciar utilizando o mecanismo de busca dinâmica-facetada, sendo que, a qualquer momento, ele poderá fazer uso da busca textual, tendo como escopo os resultados parciais obtidos até o momento.

A Figura 4 ilustra um exemplo da integração descrita acima. Neste caso, o usuário iniciou a sua busca fornecendo o termo "ontologia" para o mecanismo de busca textual. Conforme ilustrado pela Figura 4, foi obtido um conjunto de 12 documentos como resultado. Conforme pode ser observado, esse resultado parcial aparece distribuído nas diversas categorias da taxonomia, à esquerda. Desta forma, o usuário poderia dar sequência à busca, a partir do Mecanismo de Busca Dinâmica Facetada, selecionando opções sob as categorias Orientador, Tipo de Documento, Data de Publicação, Tema, etc. Textual

Figura 4 - Integração da Busca Dinâmica Facetada com a Busca

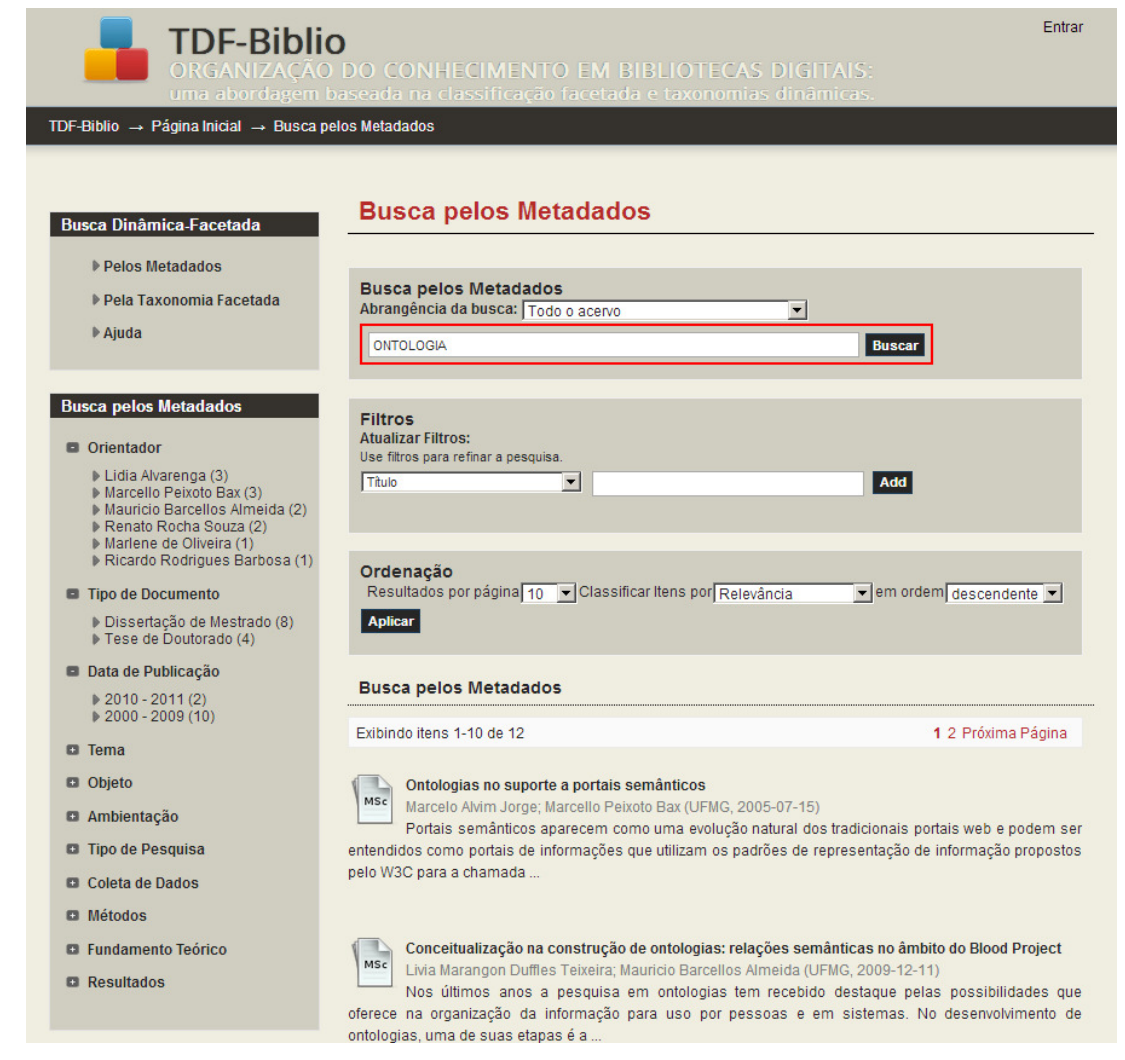

Fonte: Dados da pesquisa.

Os resultados parciais já alcançados permitem comprovar a utilidade da abordagem utilizada. A utilização de uma classificação facetada, assim como a sua implementação, fazendo uso do conceito de taxonomias 
dinâmicas para compor o mecanismo de recuperação da informação, permitem melhorar a experiência do usuário na busca e exploração do acervo da biblioteca digital. Essa melhoria pode ser observada, principalmente, em três cenários de uso:

seleção pragmática de documentos: neste caso, o usuário deseja acessar um conjunto de documentos com base em um conjunto de critérios pré-estabelecidos. Por exemplo, deseja-se encontrar todos os documentos de tipo "Tese de Doutorado" publicados a partir do ano de "2000", que tenham tido a participação de um determinado "Orientador", em uma determinada "Linha de Pesquisa";

exploração do acervo: neste caso, o usuário deseja explorar o acervo de forma livre, buscando aumentar seu nível de conhecimento acerca dos documentos e seus relacionamentos. Por exemplo, no caso de uma biblioteca de teses e dissertações, um estudante, no início de seu trabalho de pesquisa, deseja saber quais as "Metodologias" utilizadas em pesquisas sobre um determinado "Tema" ou, ainda, quais os principais "Fundamentos Teóricos" adotados nessas pesquisas; e

análise do acervo: neste caso, o usuário deseja descobrir e analisar "leis internas" ao acervo, de modo a perceber e compreender questões relacionadas ao mesmo. Por exemplo, no caso de uma biblioteca de teses e dissertações, o coordenador do Programa de Pós Graduação pode estar interessado em analisar a produção de uma determinada linha de pesquisa, quais os "Orientadores" mais produtivos, quais os "Temas" mais pesquisados, como a produção encontra-se distribuída de acordo com os documentos publicados nos últimos anos, etc.

Esses cenários demonstram a importância da capacidade exploratória oferecida pela abordagem adotada nesta pesquisa, que não pode ser encontrada nos mecanismos de recuperação da informação tradicionalmente oferecidos pelas bibliotecas digitais.

\section{Considerações finais}

Os testes iniciais do protótipo implementado já apontam para algumas vantagens da abordagem utilizada. A busca dinâmica facetada fornece suporte a um novo paradigma de acesso, permitindo a exploração guiada do acervo e fazendo uma ponte entre os processos de busca e a navegação. Além disso, o uso dessa abordagem parece ser intuitivo e facilmente utilizado pelos usuários. As taxonomias dinâmicas projetadas de forma facetada requerem um esquema conceitual simples e são capazes de se adaptar a relacionamentos novos e não previstos, permitindo aos usuários descobrir esses relacionamentos nas operações de navegação e recuperação. O controle do usuário e o mecanismo adaptativo claro e consistente proporcionado pelas taxonomias dinâmicas encorajam o usuário a experimentar e explorar, proporcionando-lhe a sensação de ter considerado todas as alternativas para chegar ao resultado. No entanto, essas vantagens deverão ser comprovadas a partir de testes com usuários, conforme previsto nas próximas etapas da pesquisa. 
Outra questão que merece destaque é a possibilidade, já explorada, de integração com outros mecanismos de recuperação da informação, como a busca textual. A busca dinâmica facetada pode ser facilmente integrada às bibliotecas digitais, assim como em outros contextos de recuperação da informação em ambientes digitais.

Finalmente, é importante destacar a importância em se resgatar importantes conhecimentos desenvolvidos no campo da Biblioteconomia e Ciência da Informação, como a Teoria da Classificação Facetada. Esses conhecimentos, utilizados em conjunto com técnicas desenvolvidas no contexto da computação e potencializados com as tecnologias da Internet, podem trazer importantes avanços nas pesquisas. Tais avanços são certamente mais fáceis de serem alcançados em contextos nos quais exista o adequado tratamento da informação, como no caso das bibliotecas digitais.

\section{Referências}

ADKISSON, H. P. Web design practices: use of faceted classification. 2005.

em:

<http://www.webdesignpractices.com/navigation/facets.html>. Acesso em: 2 set. 2010.

BARReTO, A. A. de. A condição da informação. São Paulo em Perspectiva, São Paulo, v. 16, n. 3, p. 67-74, 2002.

BRÄSCHER, M.; CAFÉ, L. Organização da informação ou organização do conhecimento? In: ENCONTRO NACIONAL DE PESQUISA E PÓSGRADUAÇÃO EM CIÊNCIA DA INFORMAÇÃO (ENANCIB), 9., 2008, São Paulo. Anais... São Paulo: Ancib, 2008.

BROUGHTON, $V$. Facet analytical theory as a basis for a knowledge organization tool in a subject portal. In: INTERNATIONAL ISKO CONFERENCE, 7., 10-13 July 2002, Granada, Spain. Proceedings of... Spain: Ergon Verlag, 2002. (Advances in Knowledge Organization, v. 8). p. $135-142$.

BROUGHTON, V. The need for a faceted classification as the basis of all methods of information retrieval. Aslib Proceedings: New Information Perspectives, v. 58, n. 1/2, p. 49-72, 2006.

BROUGHTON, $V$. A faceted classification as the basis of a faceted terminology. Axiomathes, v. 18, n. 2, p. 193-210, 2008.

CAMPOS, M. L. de A.; GOMES, H. E. Taxonomia e classificação: a categorização como princípio. In: ENCONTRO NACIONAL DE PESQUISA E PÓS-GRADUAÇÃO EM CIÊNCIA DA INFORMAÇÃO (ENANCIB), 8., 2007, Salvador. Anais... Salvador: Ancib, 2007. 
CHAN, L. M. et al. A Faceted approach to subject data in the Dublin Core Metadata Record. Journal of Internet Cataloging, v. 4, n. 1/2, p. 35-47, 2001.

DENTON, W. How to make a faceted classification and put it on the Web. Nov. 2003. Disponível em: <http://www.miskatonic.org/library/facetwebhowto.html>. Acesso em: 30 ago. 2010.

ELLIS, D.; VASCONCELOS, A. The relevance of facet analysis for World Wide Web subject organization and searching. Journal of Internet Cataloging, v. 2, n. 3/4, p. 97-114. 2000.

GARFIELD, E. A tribute to S.R. Ranganathan: part 1. Life and works. Disponível em: <http://www.garfield.library.upenn.edu/essays/v7p037y1984.pdf>. Acesso em: 28 out. 2010.

GODERT, W. Facet classification in online retrieval. International Classification, v. 18, n. 2, p. 98-109, 1991.

HJORLAND, $B$. The method of constructing classification schemes: a discussion of the state-of-the-art. In: INTERNATIONAL ISKO CONFERENCE, 7., 10-13 July 2002, Granada, Spain. Proceedings of... Spain: Ergon Verlag, 2002. (Advances in Knowledge Organization, v. 8). p. 451.

HJORLAND, B. Approaches to knowledge organization. Aula dada na University of Rome La Sapienza, 20 Abr. 2007. Disponível em: <http://www.w3.uniroma1.it/ssab/new/ApproachesToKO.zip>. Acesso em: 28 out. 2010.

HODJE, G. Systems of knowledge organization for digital libraries: beyond traditional authority files. Washington, DC, The Council on Library and Information 2000. Resources. Disponível em: <http://www.clir.org/pubs/reports/pub91/1knowledge. html>. Acesso em: 21 maio 2010.

IFLA STUDY GROUP ON THE FUNCTIONAL REQUIREMENTS FOR BIBLIOGRAPHIC RECORDS. Functional Requirements for Bibliographic Records: final report. UBCIM Publications-New Series, v. 19, 1998. Disponível em: <http://www.ifla.org/VII/s13/frbr/frbr.pdf>. Acesso em: 17 jun. 2010.

INGWERSEN, P.; WORMELLI, I. Ranganathan in the perspective of advanced information retrieval, Libri, v. 42, p. 184-201, 1992.

$\mathrm{KOCH}, \mathrm{T}$. The role of classification schemes in Internet resource description and discovery. In: TELEMATICS for Research project DESIRE: work package 3.1998 .1 Disponível em <http://www.ukoln.ac.uk/metadata/desire/classification/ >. Acesso em: 28 out. 2010.

KWASNIK, B. H. The role of classification in knowledge representation and discovery. Library Trends, v. 48, n. 1, p. 22-47, 1999. 
LA BARRE, K. The use of facetted analytico-synthetic theory as revealed in the practice of website construction and design. Ph.D thesis submitted to the School of Library and Information Science, Indiana University. 2006. LANCASTER, F. W. Indexação e resumos: teoria e prática. 2 ed. Brasília, DF: Briquet de Lemos, 2004.

MACULAN, B. C. M. dos S. Taxonomia facetada navegacional: construção a partir de uma matriz categorial para trabalhos acadêmicos. 2011. 185 f. Dissertação (Mestrado em Ciência da Informação) - Escola de Ciência da Informação, Universidade Federal de Minas Gerais, Belo Horizonte, 2011. NAVATHE, S. B.; ELMASRI, R. Fundamentals of database systems. 4 ed. Redwood City: Addison-Wesley, 2003.

NATIONAL INFORMATION STANDARDS ORGANIZATION (NISO). Seção 5.3.4 - Facet Analysis. In: Guidelines for the Construction, Format, and Management of Monolingual Controlled Vocabularies - ANSI/NISO Z39.192005, NISO, Bethseda, MD, 2005. p. 14.

SACCO, G. M.; TZITZICAS, Y. (Eds.). Dynamic taxonomies and faceted search: theory, practice, and experience. Springer-Verlag: Berlin Heidelberg, 2009.

SAYÃO, L. F. Afinal, o que é biblioteca digital? Revista USP, São Paulo, n. 80, p. 6-17, dez./fev. 2008-2009.

SPITERI, L. A simplified model for facet analysis: Ranganathan 101. Canadian Journal of Information and Library Science, v. 23, n. 1/2, p. 130, April-July 1998. Disponível em:

<http://aifia.org/pg/a_simplified_model_for_facet_analysis.php>. Acesso em: 30 ago. 2010.

TZITZIKAS, Y. et al. Extended faceted taxonomies for web catalogs. In: INTERNATIONAL CONFERENCE ON WEB INFORMATION SYSTEMS ENGINEERING, 3., 2002, Singapore. Paper presented at... WISE 2002, Singapore, December, 2002. Disponível em:

<http://www.csi.forth.gr/ tzitzik/publications/Tzitzikas_WISE_2002.ps.gz $>$ Acesso em: 22 set. 2010.

VICKERY, B. C. Faceted classification: a guide to construction and use of special schemes. London: Aslib, 1960.

VICKERY, B. C. On 'knowledge organisation'. Disponível em: <http://www.lucis.me.uk/knowlorg.htm\#start>. Acesso: 30 abr. 2010. 